\title{
Elevated Expression of Connective Tissue Growth Factor in Human Atrial Fibrillation and Angiotensin II- Treated Cardiomyocytes
}

\author{
Wen-Chin Ko, MD; Chuang-Ye Hong, MD, PhD; Shaw-Min Hou, MD; Chien-Huang Lin, PhD; \\ Eng-Thiam Ong, MD; Chwen-Fang Lee; Chia-Ti Tsai, MD, PhD; Ling-Ping Lai, MD, PhD
}

\begin{abstract}
Background: Atrial fibrosis is a feature of structural remodeling in atrial fibrillation (AF). Connective tissue growth factor (CTGF) is a potent profibrotic factor, but its role of CTGF in AF is not yet fully understood.

Methods and Results: Right atrial appendages were obtained from 20 patients who underwent cardiac surgery (10 with sinus rhythm, 10 with AF). The mRNA level, protein level and immunohistochemical staining of CTGF were significantly increased in AF patients. In a porcine AF model, tissue angiotensin II (Ang II) and CTGF levels were significantly upregulated in both atria. In perfused rat hearts, Ang II stimulation increased CTGF expression, which could be inhibited by Ang II type I receptor antagonist. In a cell culture system, both atrial fibroblasts and myocytes were responsible for the increased CTGF expression under Ang II treatment. Ang II type I receptor antagonist could inhibit the Ang II-induced CTGF expression. Treating with recombinant CTGF, atrial fibroblasts expressed an increased level of collagen I. Furthermore, the CTGF level was highly correlated with tissue Ang II content in AF pigs.
\end{abstract}

Conclusions: AF patients and animals exhibited a significantly increased expression of CTGF. Ang II stimulation upregulated CTGF expression in both atrial fibroblasts and myocytes. Ang II-induced CTGF expression might be involved in atrial substrate remodeling. (Circ $J$ 2011; 75: 1592-1600)

Key Words: Angiotensin II; Atrial fibrillation; Connective tissue growth factor

A trial fibrillation (AF) is the most common form of sustained arrhythmia in clinical practice. It is induced by suitable triggers and maintained by arrhythmogenic substrates, with reentry and triggered activity being the major mechanisms. ${ }^{1}$ The development of $\mathrm{AF}$ substrates is characterized by a combination of electrical, contractile and structural remodeling of the heart. ${ }^{2-4}$ Atrial fibrosis creates a substrate that promotes $\mathrm{AF},{ }^{5,6}$ and several signal pathways underlying atrial fibrosis have only recently been reported, including the activation of the renin-angiotensin-aldosterone system, inflammation and oxidative stress. ${ }^{7,8}$ Connective tissue growth factor (CTGF), a potent profibrotic factor, is a member of the $\mathrm{CCN}$ family (cysteine-rich61, CTGF, and nephroblastoma overexpressed) of early immediate genes. It is implicated in fibroblast proliferation, cellular adhesion, angiogenesis, and extracellular matrix (ECM) synthesis. ${ }^{9}$ CTGF has been implicated in a variety of cardiovascular pathophysiological conditions. It is overexpressed in human atherosclerotic lesions, ${ }^{10}$ and has been proven as a mediator of angiotensin II (Ang II)-induced fibrosis in vascular smooth muscle cells. ${ }^{11}$ CTGF upregulation has been found in the failing heart. ${ }^{12}$ In vitro, CTGF is induced by transforming growth factor- $\beta$ (TGF- $\beta$ ) in cardiac fibroblasts and myocytes, and upregulation of CTGF stimulates fibroblast proliferation. ${ }^{13}$ However, the role of CTGF in human AF is not fully understood as yet. We hypothesized that CTGF is overexpressed in the AF atria and that Ang II-induced CTGF expression in atrial myocytes and fibroblasts is a mechanism. In the present study, we investigated the expression of CTGF in AF patients and in a porcine AF model. We also studied

Received September 9, 2010; revised manuscript received January 29, 2011; accepted March 3, 2011; released online May 17, 2011 Time for primary review: 11 days

Graduate Institute of Clinical Medicine (W.-C.K., C.-Y.H.), Graduate Institute of Medical Sciences (C.-H.L.), College of Medicine, Taipei Medical University, Taipei; Division of Cardiology, Department of Internal Medicine, Cathay General Hospital, Taipei (W.-C.K., E-T.O.); Department of Medicine, Wang Fang Hospital, Taipei (C.-Y.H.); Division of Cardiovascular Surgery, Department of Surgery, Cathay General Hospital, Taipei (S.-M.H.); and Division of Cardiology, Department of Internal Medicine, National Taiwan University Hospital and Institute of Pharmacology, National Taiwan University Hospital, Taipei (C.-F.-L., C.-T.T., L.-P.L.), Taiwan

The last two authors are co-correspondence authors (L.P.L., C.-T.T.).

Mailing address: Ling-Ping Lai, MD, PhD, and Chia-Ti Tsai, MD, PhD, Division of Cardiology, Department of Internal Medicine,

National Taiwan University Hospital, No.1, Section 1, Jen-Ai Rd, Taipei 100, Taiwan. E-mail: fang31@ms39.hinet.net

ISSN-1346-9843 doi:10.1253/circj.CJ-10-0892

All rights are reserved to the Japanese Circulation Society. For permissions, please e-mail: cj@j-circ.or.jp 
the expression of CTGF in a perfused rat heart model and a cell culture system.

\section{Methods}

\section{Materials}

Ang II was purchased from Sigma-Aldrich (St Louis, MO, USA). Telmisartan, an Ang II type 1 receptor antagonist, and PD123319, an Ang II type 2 receptor antagonist, were also from Sigma-Aldrich. Losartan, an Ang II type 1 receptor antagonist, was obtained from Merck Research Laboratories (West Point, NY, USA). Recombinant CTGF was from Peprotech (Rocky Hill, CT, USA).

\section{Patients}

After written informed consent was given, atrial tissue samples from the right atrial appendage was obtained from patients undergoing cardiac bypass surgery or mitral/aortic valve replacement. Tissue samples were taken from 10 consecutive patients with chronic or persistent $\mathrm{AF}$ ( $>6$ months) and from 10 matched control patients with no history of AF (ie, in SR).

\section{Immunohistochemistry}

Immunohistochemistry for localization of CTGF was performed in a total of 12 tissue specimens ( 6 controls, 6 AF). Sections from formalin-fixed and paraffin-embedded specimens were stained with hematoxylin and eosin. Immunostaining was performed with rabbit polyclonal antibodies to CTGF (AbCam ab5097; AbCam, Cambridge, UK) following standard protocols. The specificity of the detected signals was controlled by omitting the primary antibodies. All immunohistochemistry was analyzed by light microscopy using Image-Pro Plus (Media Cybernetics, Crofton, MA, USA) computer image analysis software. For quantification of ECM, tissue blocks were cut into $6-\mu \mathrm{m}$ sections and deparaffinized for Masson trichrome staining. We analyzed 20 randomly chosen vessel-free fields of each tissue at $\times 200$ magnification, and a square area was identified in each microscopic field. The extent of ECM in each field was defined as the percent area of ECM (ECM\%) and calculated as: (area of ECM/ total tissue area) $\times 100 \% .{ }^{14}$

\section{Porcine Model of AF}

We used 12 adult Yorkshire-Landrace pigs (weight $65 \pm 13 \mathrm{~kg}$, range $50-81 \mathrm{~kg}$; 6 in the AF group, 6 in the control group). Under intravenous anesthesia with thiamylal $(2-3 \mathrm{mg} / \mathrm{kg}$; Kyorin Pharmaceutical Co, Tochigi, Japan), all animals were transvenously implanted with a high-speed pacemaker (ItrelIII, Medtronic, Inc, Minneapolis, MN, USA). The pacemaker continuously paced the right atria at a rate of 600 beats $/ \mathrm{min}$ in the AF group for 4 weeks, after which the atrial pacemaker was turned off and the pigs were in AF. The pigs were humanely killed 2 weeks after the pacemakers were turned off. In the control group, the pacemaker remained off for 6 weeks after implantation. Transmural tissue blocks were obtained from the free wall of both the right atrium (RA) and left atrium (LA). ${ }^{14}$

\section{Rat Heart Perfusion}

Wistar rats weighing approximately $300 \mathrm{~g}$ were humanely killed $10 \mathrm{~min}$ after heparin and pentobarbital injections. The hearts were isolated and perfused using Langendorff apparatus and $37^{\circ} \mathrm{C}$ Tyrode solution for $5 \mathrm{~min}$. Experimental rat hearts were perfused with $37^{\circ} \mathrm{C}$ Tyrode buffer containing $10^{-6} \mathrm{~mol} / \mathrm{L}$ Ang II. At the end of perfusion $(1-1.5 \mathrm{~h})$, the atria were separated and lysed for protein and RNA extraction. The control rat hearts were perfused with $37^{\circ} \mathrm{C}$ Tyrode buffer only for $1 \mathrm{~h}$. The drug treatment group was pre-perfused with $10^{-6} \mathrm{~mol} / \mathrm{L}$ losartan for $30 \mathrm{~min}$ then perfused with $37^{\circ} \mathrm{C}$ Tyrode buffer containing $10^{-6} \mathrm{~mol} / \mathrm{L}$ Ang II for $1 \mathrm{~h}$. Animal use in the present study conformed to the Guide for the Care and Use of Laboratory Animals (National Institutes of Health publication No. 85-23, revised 1996) and was approved by the Institutional Animal Care and Use Committee of the National Taiwan University.

\section{Culture of Atrial Myocytes and Fibroblasts}

Both atria from 1-week-old neonatal Wistar rats were cut into chunks and subjected to trypsin $(0.125 \%)$ digestion in a balanced salt solution. The disaggregated cells were collected by centrifugation at $300 \mathrm{~g}$ for $10 \mathrm{~min}$. The cell pellet was resuspended in serum-containing medium (Ham's F-12:DMEM; $1: 1$ with $20 \%$ fetal bovine serum and $1 \%$ penicillin-streptomycin), plated onto a Petri dish and kept for $2.5 \mathrm{~h}$ in a $5 \% \mathrm{CO}_{2}$ atmosphere at $37^{\circ} \mathrm{C}$ to allow non-cardiomyocytes to attach to the dish. Non-cardiomyocytes (mostly fibroblasts) that attached to the bottom of the dish were subsequently incubated with DMEM supplemented with $10 \%$ fetal calf serum and $1 \%$ penicillin-streptomycin for 3 additional days. The suspended nonattached cardiomyocytes in the medium were collected and cultured for 3 additional days (Ham's F-12:DMEM; 1:1 with $20 \%$ fetal bovine serum and $1 \%$ penicillin-streptomycin). After 3 days, the cells were transferred to a serum-free medium (Ham's F-12:DMEM; 1:1 for myocytes and DMEM for nonmyocytes) for $24 \mathrm{~h}$ and then used in the experiments. Cardiac fibroblasts were identified by characteristic morphology and positive staining with antibody to vimentin $(>90 \%) .{ }^{15}$

\section{Total RNA Isolation and Real-Time Reverse Transcription Polymerase Chain Reaction (PCR)}

Total cellular RNA was extracted using a Paris $^{\mathrm{TM}}$ Isolation Kit (Ambion Inc) for cell cultures and a Qiagene RNAeasy kit for myocardial tissues according to the manufacturers' protocols. Samples were evaluated for quality and quantity using a Hitachi U-2000 Spectrophotometer. TaqMan ${ }^{\circledR}$ Gene Expression Assays (Applied Biosystems, Foster City, CA, USA) were used to quantify gene expression. Total RNA was reverse-transcribed to cDNA, which was used as a template to perform the second step of real-time PCR using TaqMan ${ }^{\circledR}$ Gene Expression Assays. The expression of CTGF was investigated and the expression of glyceraldehyde 3-phosphate dehydrogenase (GAPDH) was used as an internal control. All gene expression assays had a FAM ${ }^{\mathrm{TM}}$ reporter dye at the 5' end of the TaqMan ${ }^{\circledR}$ MGB probe and a nonfluorescent quencher at the 3' end of the probe. The real-time PCR reactions were performed in an ABI Prism ${ }^{\circledR}$ system instrument and the thermal cycling parameters were run as described in the data sheet. The results of real-time PCR were expressed as $2^{-\Delta \Delta C_{T}}$ values.

\section{SDS-PAGE and Western Blotting}

Proteins were extracted with lyses buffer containing $50 \mathrm{mmol} / \mathrm{L}$ Tris- $\mathrm{HCl} \mathrm{pH} 7.5,5 \mathrm{mmol} / \mathrm{L}$ EDTA, $10 \mathrm{mmol} / \mathrm{L}$ EGTA, $10 \mu \mathrm{g} / \mathrm{ml}$ aprotinin, $10 \mu \mathrm{g} / \mathrm{ml}$ leupeptin, $10 \mu \mathrm{g} / \mathrm{ml}$ pepstatin A, and $50 \mu \mathrm{g} / \mathrm{ml}$ phenylmethylsulfonyl fluoride. Samples were placed on ice for $15 \mathrm{~min}$ and centrifuged at $10,000 \mathrm{~g}$ for $10 \mathrm{~min}$. The supernatant was removed and the protein concentration was determined using the BCA Protein Assay. The lysates were denatured and resolved on $12 \%$ sodium dodecyl sulfate-polyacrylamide gel electrophoresis 


\begin{tabular}{|c|c|c|c|c|c|c|c|c|}
\hline Age, years & Sex & $\begin{array}{c}\text { Duration } \\
\text { of AF, } \\
\text { months }\end{array}$ & $\begin{array}{c}\text { No. of } \\
\text { diseased } \\
\text { coronary } \\
\text { arteries }\end{array}$ & VD & $E F, \%$ & $\begin{array}{c}\text { LA } \\
\text { diameter, } \\
\mathbf{m m}\end{array}$ & $\begin{array}{l}\text { History of } \\
\text { HT/DM }\end{array}$ & Drug therapy \\
\hline \multicolumn{9}{|c|}{ Sinus rhythm $(n=10)$} \\
\hline 67 & $M$ & & 3 & - & 53 & 25 & Both & As, $A, L, N$ \\
\hline 72 & $\mathrm{~F}$ & & 3 & MR & 15 & 42 & - & As, A, D, L \\
\hline 69 & $\mathrm{~F}$ & & 3 & - & 56 & 30 & DM & As, $\mathrm{B}, \mathrm{N}$ \\
\hline 71 & $M$ & & 3 & - & 55 & 26 & $\mathrm{HT}$ & $A, C, N$ \\
\hline 73 & M & & - & MR & 65 & 38 & Both & B, Co \\
\hline 80 & $M$ & & 3 & $\mathrm{AR}, \mathrm{MR}$ & 45 & 29 & - & As, A \\
\hline 48 & $M$ & & 2 & AS & 32 & 45 & - & A, B, Co, D, L \\
\hline 78 & $\mathrm{~F}$ & & - & AS, MR & 60 & 36 & Both & As, A, B, N \\
\hline 85 & $\mathrm{~F}$ & & 3 & MR & 28 & 27 & $\mathrm{HT}$ & As, A, C, N, L \\
\hline 68 & $M$ & & 3 & MR & 28 & 35 & $\mathrm{HT}$ & $A, D, N$ \\
\hline \multicolumn{9}{|l|}{ Total } \\
\hline $71.1 \pm 9.9$ & $6 \mathrm{M} / 4 \mathrm{~F}$ & & 8 Patients & 7 Patients & $43.7 \pm 16.8$ & $33.3 \pm 6.9$ & & \\
\hline \multicolumn{9}{|l|}{$A F(n=10)$} \\
\hline 71 & M & 60 & 2 & AS, MR & 55 & 55 & Both & A, Co, D, L \\
\hline 64 & M & 12 & 1 & AR, MR & 72 & 57 & - & As, A, C, \\
\hline 75 & $M$ & 132 & 1 & $\mathrm{AR}, \mathrm{MR}$ & 63 & 44 & - & A, B, Co, D \\
\hline 72 & $M$ & 18 & 1 & MR & 64 & 42 & $\mathrm{HT}$ & Co, D \\
\hline 63 & $M$ & 62 & 2 & AR, MS & 35 & 79 & Both & As, A, D, L \\
\hline 80 & $\mathrm{~F}$ & 9 & 3 & - & 42 & 41 & Both & As, A, B \\
\hline 64 & M & 7 & 2 & MR & 71 & 56 & - & A, B, Co, D, L \\
\hline 78 & $\mathrm{~F}$ & 13 & 1 & MR & 40 & 51 & - & B, Co, D, L \\
\hline 77 & $\mathrm{~F}$ & 120 & - & AS, MR & 62 & 68 & $\mathrm{HT}$ & As, A, C, D, L \\
\hline 62 & $M$ & 16 & 3 & - & 30 & 49 & Both & As, A, B, C, L \\
\hline \multicolumn{9}{|l|}{ Total } \\
\hline $70.6 \pm 6.9$ & $7 \mathrm{M} / 3 \mathrm{~F}$ & $44.9 \pm 47.2$ & 9 Patients & 8 Patients & $53.4 \pm 15.3$ & $54.2 \pm 11.9^{*}$ & & \\
\hline
\end{tabular}

${ }^{*} \mathrm{P}<0.05$ vs. sinus rhythm.

$A F$, atrial fibrillation; VD, valve disease requiring valve replacement; EF, ejection fraction; LA, left atrial; HT, hypertension; DM, diabetes mellitus; As, aspirin; A, angiotensin-converting enzyme inhibitors; L, loop diuretics; N, nitrates; MR, mitral regurgitation; D, digoxin; B, beta-blockers; C, calcium-channel blockers; Co, coumadin; AR, aortic regurgitation; AS, aortic stenosis; MS, mitral stenosis.

(SDS-PAGE, Hoefer Dual Gel Caster). The resolved proteins were then transferred to PVDF membranes for $90 \mathrm{~min}$ at $150 \mathrm{~V}$ using a Hoefer ${ }^{\mathrm{TM}}$ TE70 semi-dry transfer unit. The fresh blot was blocked with $1 \%$ skim milk, and analyzed with antibodies against CTGF (Abcam 1:1,000), collagen I (GeneTex 1:1,000), GAPDH (Chemicon 1:600) or $\beta$-actin (Sigma $1: 10,000)$ for $90 \mathrm{~min}$ at room temperature. This was followed by incubation with a secondary antibody conjugated with horseradish peroxidase for $1 \mathrm{~h}$ at room temperature. Immunoreactive bands were visualized using an enhanced chemiluminescence system, Western Lightning ${ }^{\mathrm{TM}}$ (Perkin Elmer Labs, Inc). Spot densitometry was performed by using an Alpha Innotech Multimage Light Cabinet.

\section{Measurement of Tissue Ang II Concentration}

Ang II concentration was measured by enzyme-linked immunosorbent assay (ELISA). Protein samples (400-700 $\mu \mathrm{g}$ ) were analyzed in a microtiter plate with an anti-Ang II antibody (Peninsula Laboratories, Belmont, CA, USA) and biotinylated Ang II. The microplate was washed 5 times with TBST (Tris-based buffer with Tween) and treated with streptavidin-horseradish peroxidase. The color reaction was developed with $100 \mathrm{ml}$ tetramethylbenzidine substrate and terminated with $100 \mathrm{ml} 2 \mathrm{~N} \mathrm{HCl}$. Absorbance at $450 \mathrm{~nm}$ was recorded, and the concentration $(\mathrm{ng} / \mathrm{ml})$ was calculated from a standard curve.

\section{Statistical Analysis}

Continuous variables are presented as the mean \pm SEM. Intergroup differences were analyzed by 1-way ANOVA for comparisons among 3 or more groups and the independent Student's t-test for comparisons between 2 groups. A probability value $<0.05$ was regarded as significant. Chi-square analysis was used to examine the relationships among categorical variables.

\section{Results}

Increased CTGF Expression and ECM in the RA of AF Patients The clinical characteristics of the study subjects are shown in Table. AF patients had a greater mean LA dimension than patients in $\mathrm{SR}(54.2 \pm 11.9 \mathrm{~mm}$ vs. $33.3 \pm 6.9 \mathrm{~mm}, \mathrm{n}=10, \mathrm{P}<0.05)$. There were no significant differences between the AF and SR patients for other clinical variables detected. When compared with SR patients, the mRNA level of CTGF was significantly higher in AF patients $(\mathrm{P}<0.01$; Figure $1 \mathrm{~A})$. Analysis by western blotting also showed a significantly higher CTGF protein level in AF patients compared with $\mathrm{SR}$ patients $(\mathrm{P}<0.05$; Figure 1B). The LA diameter was exponentially associated with CTGF level (r=0.7, P=0.001; Figure 1C), which indi- 
A

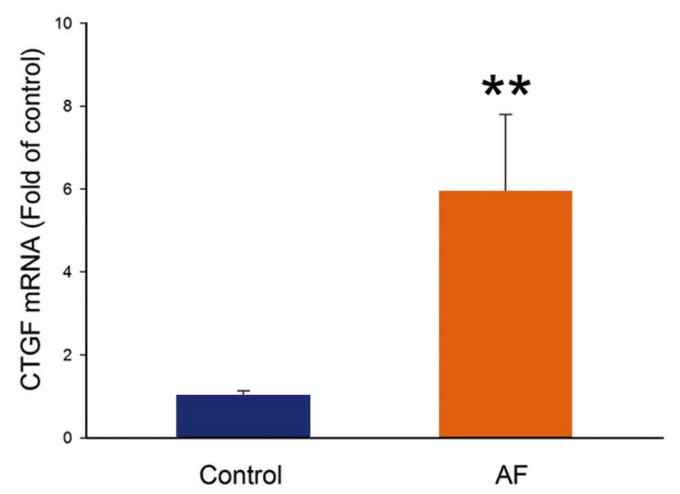

C

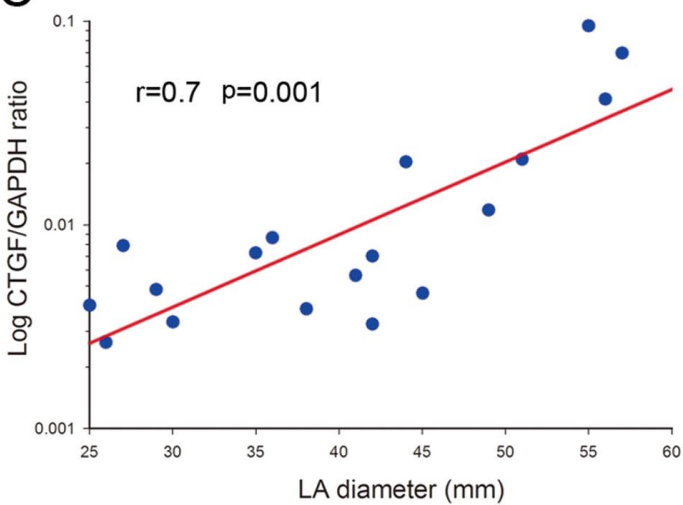

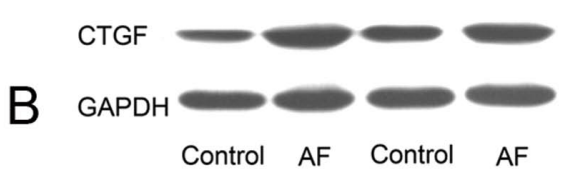

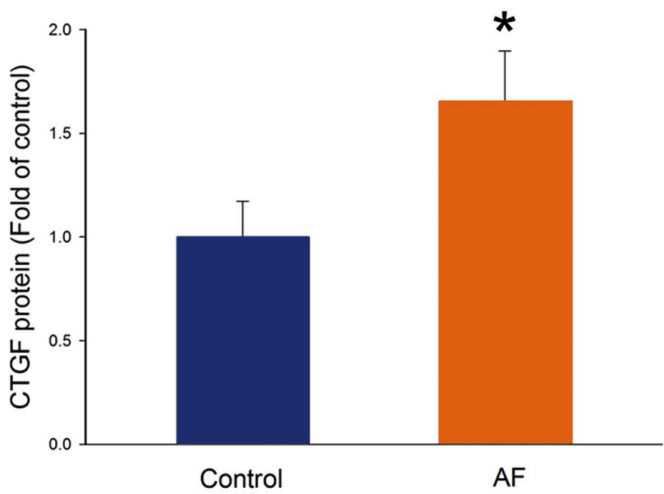

Figure 1. Expression of CTGF in patients with AF and controls. (A) When compared with controls, AF patients showed increased levels of CTGF mRNA as measured by quantitative real-time reverse transcription polymerase chain reaction. (B) On western blots, patients with AF showed significantly increased levels of CTGF protein. Results are mean $\pm S E M$ of 10 samples. ${ }^{*} \mathrm{P}<0.05$ vs. control, ${ }^{\star *} P<0.01$ vs. control. (C) Positive correlation between left atrial size and mRNA expression of CTGF for patients with left atrial diameter $\leq 65 \mathrm{~mm} . \mathrm{n}=18, \mathrm{r}=0.7, \mathrm{P}=0.001$. AF, atrial fibrillation; CTGF, connective tissue growth factor; LA, left atrium.

cated that LA size was strongly associated with CTGF expression. CTGF levels and ECM were increased in RA tissue from patients with AF. Quantification of the ECM stained by Masson's trichrome showed a significantly greater ECM\% in AF patients as compared with SR patients $(33.0 \pm 1.1 \%$ vs. $9.5 \pm 4.2 \%, \mathrm{n}=6, \mathrm{P}<0.01$; Figure 2).

\section{Elevated CTGF Expression in Both Atria in the Porcine Model of AF}

To evaluate the CTGF expression in each atrium, we measured mRNA and protein levels of CTGF in both atria from a porcine pacing-induced AF model. Analysis of real-time reverse transcription polymerase chain reaction data showed that mRNA levels of CTGF expression were significantly increased in both atria of the paced pigs as compared with that of controls ( $\mathrm{n}=6, \mathrm{P}<0.01$, LA of paced pigs vs. control; $\mathrm{P}<0.05$, RA of paced pigs vs. control; Figure 3A). Protein levels of CTGF expression were significantly increased in both atria of the paced pigs as compared with that of controls $(\mathrm{n}=6, \mathrm{P}<0.05$,
LA of paced pigs vs. control; $\mathrm{P}<0.05$, RA of paced pigs vs. control; Figure 3B). The LA size of the paced pigs measured by echocardiography was significantly greater than that of the controls ( $34 \pm 5$ vs. $25 \pm 3 \mathrm{~mm}, \mathrm{n}=6, \mathrm{P}<0.01)$. We also measured Ang II levels in the porcine atrial tissues and found significantly higher levels of tissue Ang II in the paced pigs as compared with controls. In the LA, tissue Ang II concentrations were significantly higher in the paced pigs than in controls (70.6 \pm 14.9 vs. $30.4 \pm 13.0 \mathrm{pg} / \mathrm{mg}$ protein, $\mathrm{P}<0.01)$. In the $\mathrm{RA}$, tissue Ang II concentrations were also significantly higher in the paced pigs than in controls $(81.2 \pm 16.8$ vs. $42.4 \pm 15.2 \mathrm{pg} / \mathrm{mg}$ protein, $\mathrm{P}<0.01)$.

\section{Increased CTGF Expression in Atria But Not Ventricles of Ang II-Perfused Rat Hearts}

To evaluate the CTGF expression in atria and ventricles, we measured both mRNA and protein levels of CTGF in rat hearts after $1 \mathrm{~h}$ of Ang II perfusion. Compared with controls, Ang II-perfused rat atria had a significantly increased expres- 
CTGF (DAB)

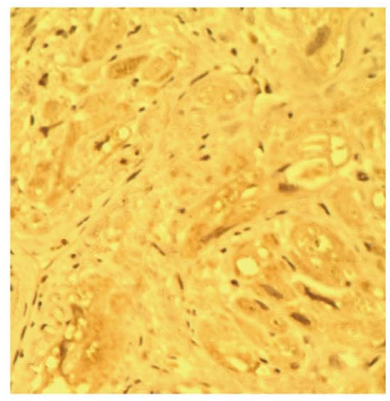

AF

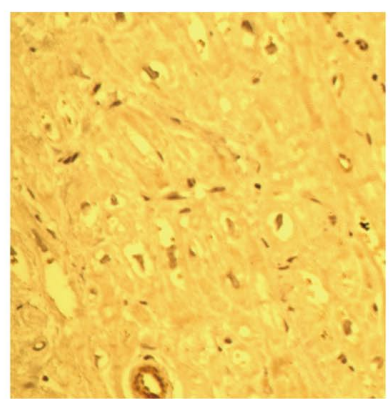

CTGF (FITC)
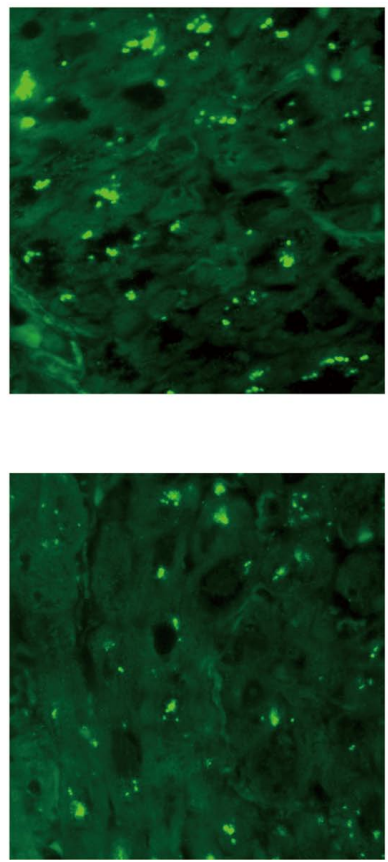

TRICHROME
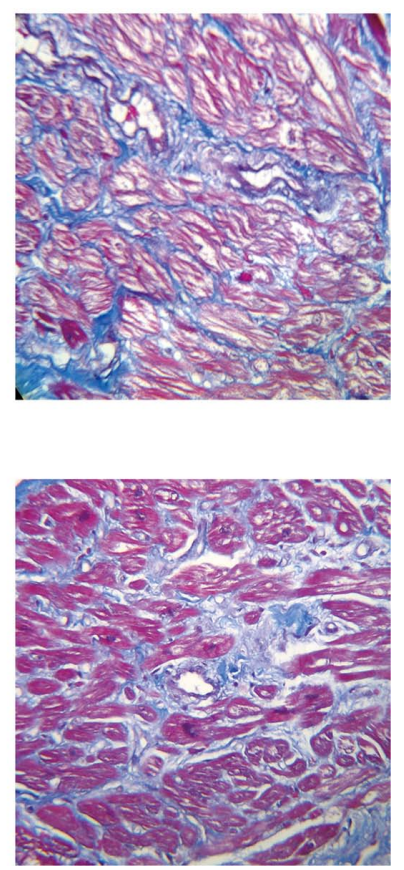

Figure 2. Representative immunohistochemical sections of right atrial walls showed increased staining for CTGF in patients with AF compared with patients in sinus rhythm. Immune complexes were detected with diaminobenzidine substrate (DAB) and fluorescein isothiocyanate (FITC). Masson's trichrome staining revealed more extracellular matrix and fibrosis in AF patients (33.0 $\pm 1.1 \mathrm{ECM} \%$ vs. $9.5 \pm 4.2 \% \mathrm{ECM} \%, \mathrm{n}=6$ per group, $\mathrm{P}<0.01$ vs. control). Original magnification $\times 200$. AF, atrial fibrillation; CTGF, connective tissue growth factor.

A

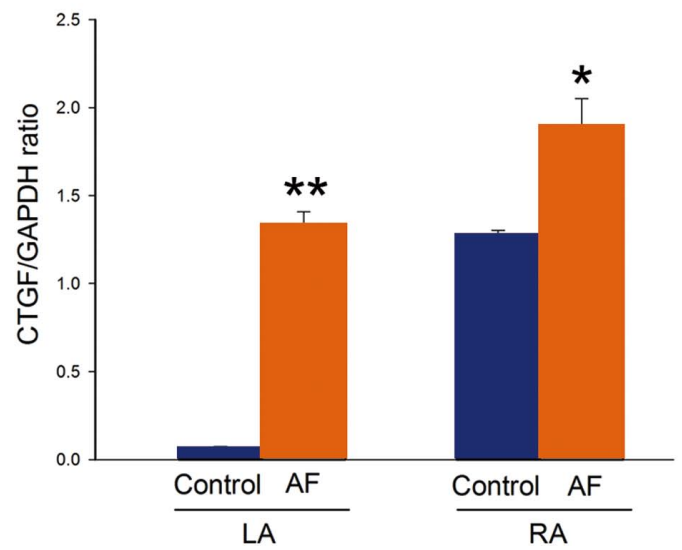

B

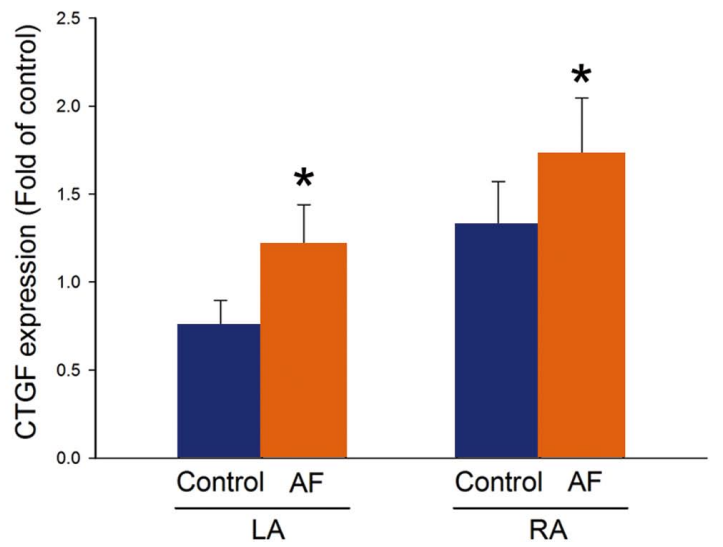

Figure 3. Expression of CTGF in porcine atria after rapid atrial depolarization for 6 weeks. (A) When compared with controls, AF pigs had a significantly higher level of CTGF mRNA in their left and right atria as measured by quantitative real-time reverse transcription polymerase chain reaction. (B) On western blots, paced pigs showed a significantly higher level of CTGF protein in the left and right atria. Results are mean \pm SEM of 6 samples. ${ }^{\star} P<0.05$ vs. control, ${ }^{* *} P<0.01 \mathrm{vs}$. control. AF, atrial fibrillation; CTGF, connective tissue growth factor; GAPDH, glyceraldehyde 3-phosphate dehydrogenase; LA, left atrium; RA, right atrium. 
A

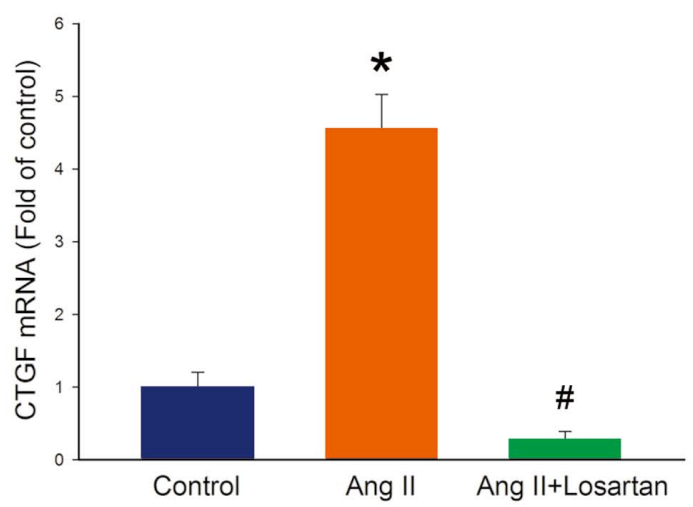

C

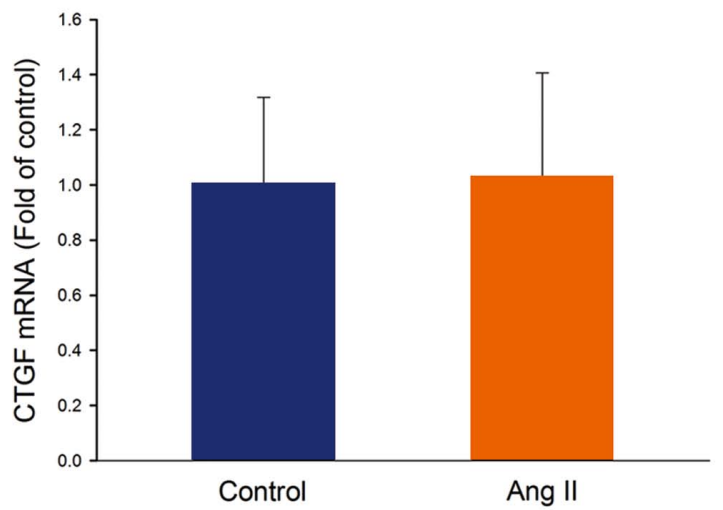

B

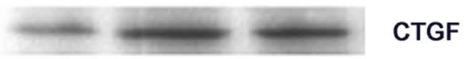

$\longrightarrow$ Actin

Control Ang II Ang II+Losartan

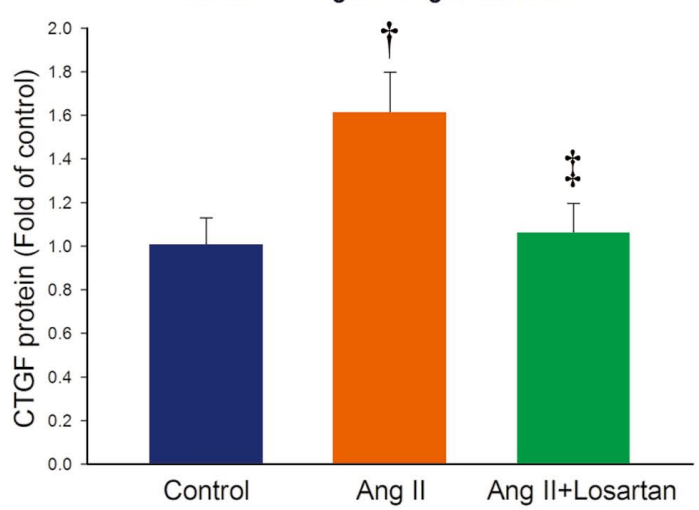

D

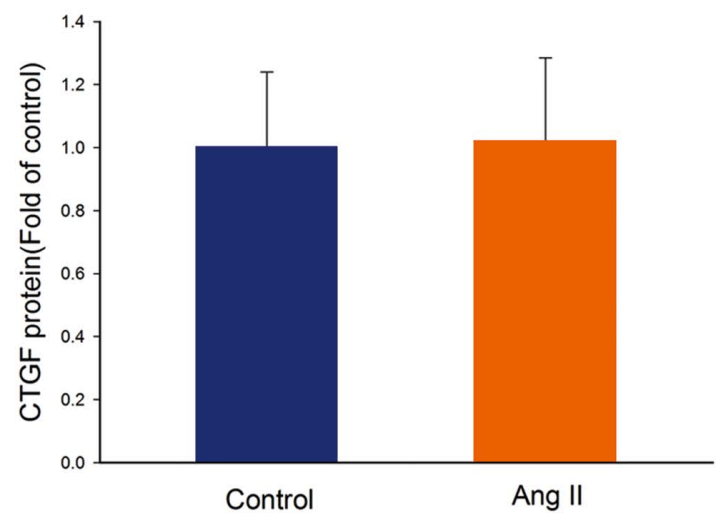

Figure 4. Expression of CTGF in rat hearts after $1 \mathrm{~h}$ of Ang II perfusion. (A) When compared with controls, Ang II-perfused rat atria showed increased levels of CTGF MRNA as measured by quantitative real-time reverse transcription polymerase chain reaction. The increased expression of CTGF was significantly inhibited by perfusion with $10^{-6} \mathrm{~mol} / \mathrm{L}$ losartan for $30 \mathrm{~min}$ before Ang $\|$ perfusion. $n=6,{ }^{*} P<0.01$ vs. control and ${ }^{\#} P<0.01$ vs. Ang II-perfused rat hearts. (B) On western blots, Ang II-perfused rat atria showed significantly increased levels of CTGF protein. The increased expression of CTGF was significantly inhibited by perfusion with $10^{-6} \mathrm{~mol} / \mathrm{L}$ losartan for $30 \mathrm{~min}$ before Ang II perfusion. ${ }^{\top} \mathrm{P}<0.05$ vs. control and $\ddagger \mathrm{P}<0.05$ vs. Ang II-perfused rat hearts. (C,D) No significant differences in CTGF levels between controls and Ang II-perfused rat ventricles. $n=3, P=0.96$ and $\mathrm{P}=0.96$, respectively. AF, atrial fibrillation; Ang II, angiotensin II; CTGF, connective tissue growth factor.

sion of CTGF mRNA and protein $(\mathrm{n}=6, \mathrm{P}<0.01$ and $\mathrm{P}<0.05$, respectively; Figures 4A,B). The increased expressions of CTGF mRNA and protein were significantly inhibited by perfusion with losartan for $30 \mathrm{~min}$ before Ang II perfusion ( $\mathrm{n}=6$, $\mathrm{P}<0.01$ and $\mathrm{P}<0.05$, respectively; Figures $4 \mathrm{~A}, \mathrm{~B}$ ). However, there were no significant differences in CTGF mRNA and protein levels between control and Ang II-perfused rat ventricles $(n=3, P=0.96$ and $P=0.96$, respectively; Figures $4 C, D)$.

\section{Ang II-Induced CTGF mRNA Expression in Primary Fibroblast and Cardiomyocyte Culture}

To elucidate the cell type that is responsible for CTGF production in the heart, we measured both mRNA and protein levels of CTGF from atrial fibroblast and myocyte cultures treated with Ang II. When compared with controls, Ang II induced a significant increase of CTGF mRNA expression in both atrial fibroblasts and myocytes in $1 \mathrm{~h}(\mathrm{n}=4, \mathrm{P}<0.01$ and
$\mathrm{P}<0.05$, respectively; Figures 5A, B). Ang II increased CTGF mRNA expression in both atrial fibroblasts and myocytes in a dose-dependent manner $(\mathrm{n}=3, \mathrm{P}<0.01$ and $\mathrm{P}<0.01$, respectively; Figures 5C,D). The increased expression of CTGF in atrial fibroblasts was significantly inhibited by pretreatment with $10^{-6} \mathrm{~mol} / \mathrm{L}$ telmisartan, an Ang II type 1 receptor antagonist, for $30 \mathrm{~min}(\mathrm{P}<0.01$; Figure 6). Pretreatment with $10^{-6} \mathrm{~mol} / \mathrm{L}$ PD123319, an Ang II type 2 receptor antagonist, failed to inhibit the Ang II-induced CTGF mRNA expression in atrial fibroblasts ( $\mathrm{P}=\mathrm{NS}$; Figure 6).

To validate the finding in the cellular study, we also evaluated the correlation between tissue Ang II and CTGF levels in our porcine AF model. We found highly correlated tissue Ang II and CTGF levels ( $\mathrm{r}=0.8, \mathrm{P}=0.01$; Figure 7), suggesting that the increased tissue CTGF level in the AF pigs might be due to increased tissue Ang II levels. To verify the causal relationship between CTGF and atrial fibrosis, cultured atrial fibroblasts 

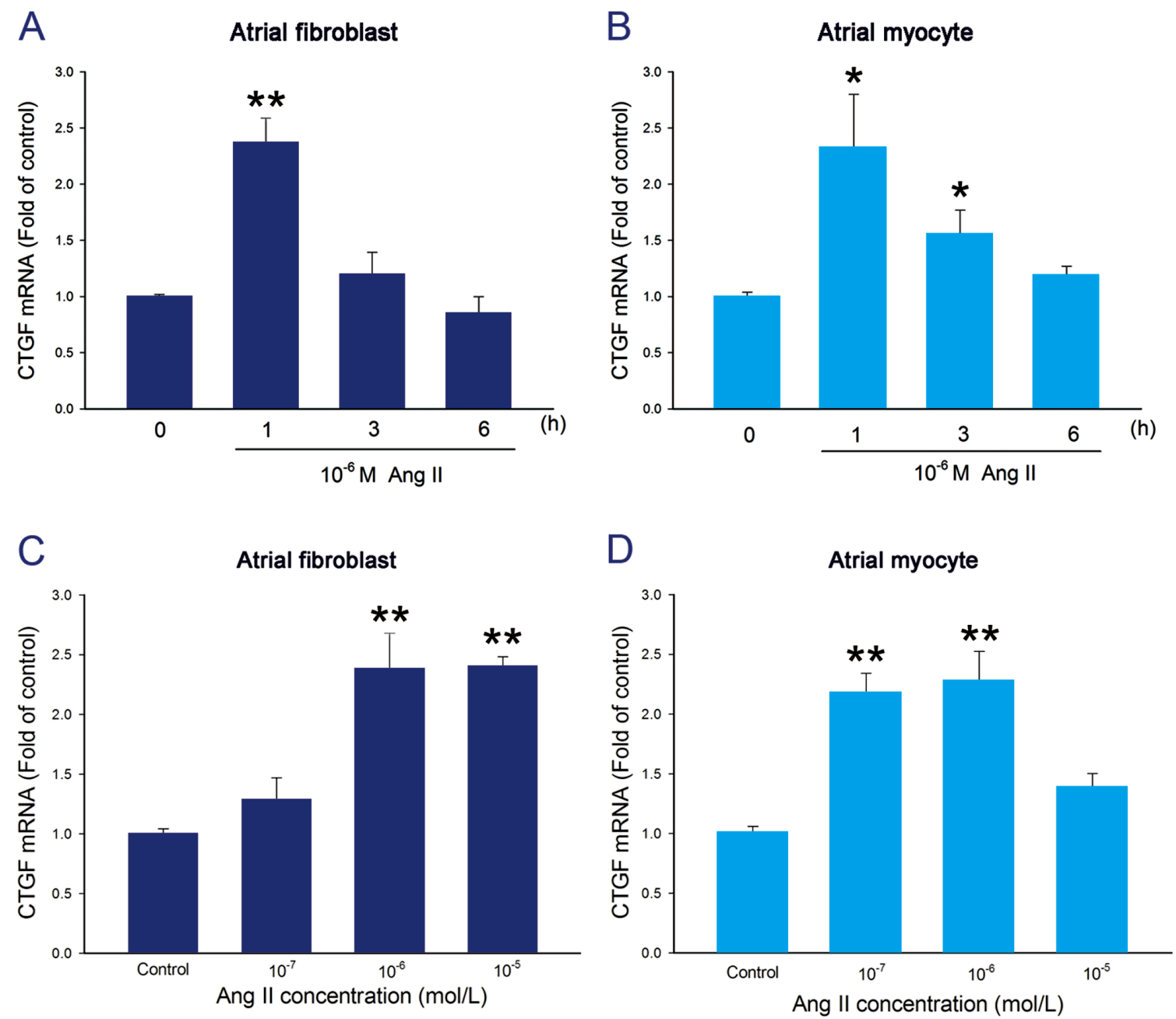

Figure 5. Expression of CTGF in atrial fibroblast and myocyte cultures after Ang II treatment. (A,B) Ang II induced increased levels of CTGF mRNA in both atrial fibroblasts and myocytes in $1 \mathrm{~h}$ as measured by quantitative real-time reverse transcription polymerase chain reaction. $n=4,{ }^{*} \mathrm{P}<0.01$ vs. control and ${ }^{*} \mathrm{P}<0.05$ vs. control. (C, D) Ang II increased CTGF mRNA expression in both atrial fibroblasts and myocytes in a dose-dependent manner in $1 \mathrm{~h} . \mathrm{n}=3,{ }^{\star \star} \mathrm{P}<0.01 \mathrm{vs}$. control. AF, atrial fibrillation; Ang $\|$, angiotensin II; CTGF, connective tissue growth factor.

were treated with recombinant CTGF $(300 \mathrm{ng} / \mathrm{ml}$ for $24 \mathrm{~h})$. CTGF treatment resulted in significantly increased expressions of collagen I mRNA and protein (data not shown).

\section{Discussion}

Atrial fibrosis is strongly associated with $\mathrm{AF},{ }^{16}$ but the precise mechanism and signaling pathways involved in the development of atrial fibrosis are largely unknown. ${ }^{17}$ The present study reports that (1) patients with AF had increased CTGF expression in the RA; (2) CTGF expression was elevated in both atria of a porcine AF model; (3) Ang II infusion induced CTGF expression in rat atria but not ventricles; and (4) both cardiac fibroblasts and cardiomyocytes were responsible for the increased CTGF expression.

CTGF is a 38-kDa cysteine-rich, secreted, heparin-binding and ECM-associated protein involved in multiple cellular events, including ECM production, cell adhesion, cell proliferation and, in some cell types, apoptosis, as well as more complex biological processes such as tumorigenesis, angiogenesis, and wound healing. ${ }^{18,19}$ Cardiac fibroblasts, together with cardiomyocytes, play an essential role in the progression of cardiac remodeling. Injury might evoke multiple signaling pathways in cardiac cells that lead to coordinated and sequential gene regulation. ${ }^{20}$ It has been reported that mechanical stretch of cardiomyocytes induces the release of Ang II, which stimulates the release of growth factors and cytokines from cardiac fibroblasts. These factors exert their effects on both fibroblasts and cardiomyocytes. ${ }^{21}$ It is logical to postulate that electromechanical stimulation of cardiomyocytes during $\mathrm{AF}$ induces the release of cytokines, including Ang II and CTGF. In our current porcine AF model, CTGF expression and Ang II level were increased in both atria after rapid atrial pacing. The total amount of CTGF expression was greater in the RA than in the LA, in both SR and AF pigs. However, the increase in CTGF expression was greater in the LA of AF pigs. There are certain regional differences in basal protein expression in the heart, such as cytochrome P450 mono-oxygenases and 


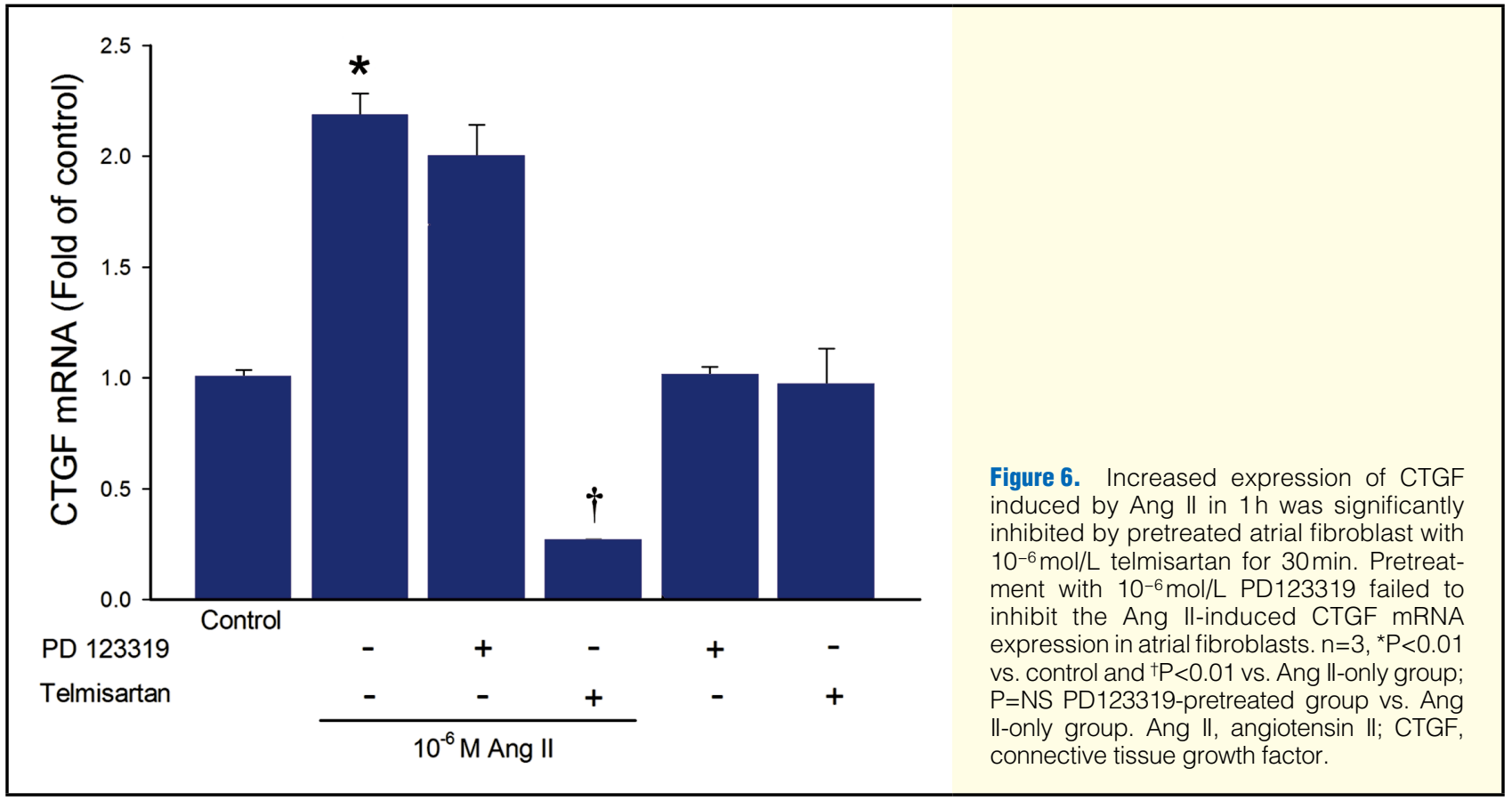

brain natriuretic peptide. ${ }^{22,23}$ Therefore, it is possible that basal expression of CTGF is higher in the RA. Although the electrical stimulation sites were in the RA, the increase in CTGF expression was greater in the LA of AF pigs, which suggests that rapid depolarization of the atria rather than electrical stimulation plays the critical role. In human AF, higher atrial Ang II levels were found in our previous study..$^{15}$ In the present study, we also showed that AF patients had increased CTGF expression in the RA. CTGF expression was also found to be higher in LA from AF patients in a recent report. ${ }^{24}$ There are substantial atrial-ventricular differences in remodeling. It has been showed that Ang II receptor density ${ }^{25}$ and platelet-derived growth factor receptor gene expression ${ }^{26}$ are higher in atria than in ventricles. In this study, we also found that Ang II induced CTGF expression in rat atria but not in rat ventricles. Our previous study also showed that the atrium is more susceptible to Ang II stimulation than the ventricle in Janus kinase (JAK)/signal transducers and activators of transcription (STAT) activation. ${ }^{15}$

Within 5 years, $24 \%$ of paroxysmal AF patients progress slowly to chronic AF. ${ }^{27}$ There are certain factors initiating substrate remodeling and subsequent progression of AF. ${ }^{28,29}$ CTGF is an immediate early gene and an active secretary growth factor. ${ }^{30,31}$ In addition to stimulating collagen synthesis and causing fibroblast proliferation, ${ }^{32}$ CTGF also induces hypertrophy and apoptosis in cardiomyocytes. ${ }^{33}$ In this study, we found that CTGF expression was elevated in the atria of AF patients. We also demonstrated that after $1 \mathrm{~h}$ of Ang II perfusion, rat hearts rapidly expressed increased CTGF mRNA and protein expressions. Atrial fibroblasts and cardiomyocytes both expressed increased CTGF mRNA soon after Ang II stimulation. Regarding atrial fibrosis, the renin-angiotensin system, TGF- $\beta 1$ and oxidative stress pathway have been reported to play important roles. ${ }^{17}$ Tissue hypoxia and local immunologic inflammatory responses are other mechanisms in atrial fibrosis that have been proposed recently. ${ }^{34,35}$ From the results of our current study, we think that CTGF is a new important pathway in atrial structural

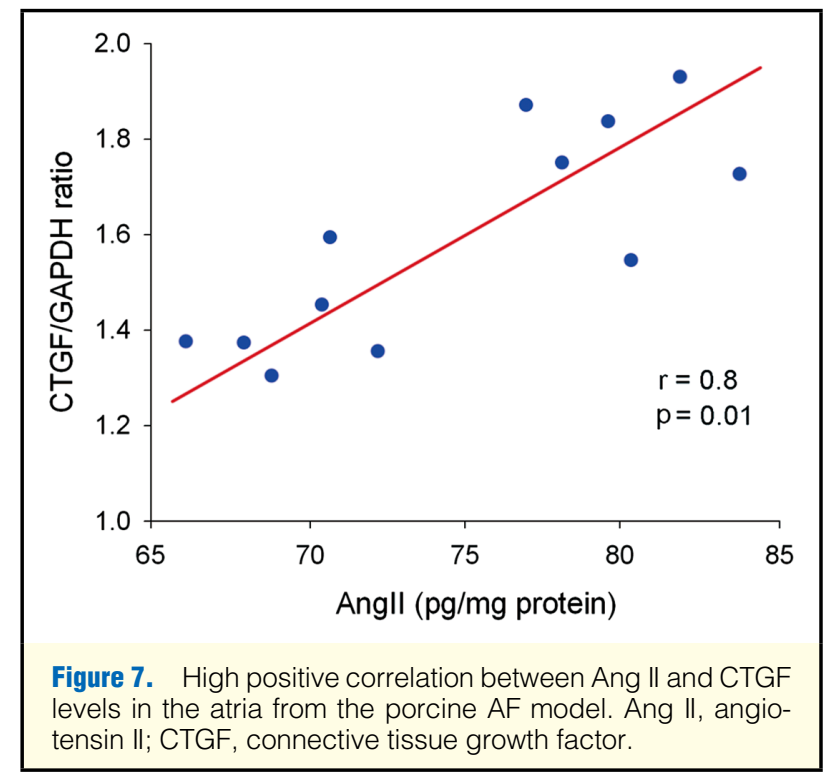

remodeling, and it might be a potential target for developing upstream AF therapy.

As for the mechanism of CTGF expression during AF, in our previous study we showed that in atrial myocytes, rapid depolarization induced a sustained elevation of intracellular calcium, and upregulation of angiotensin-converting enzyme, chymase and angiotensinogen, resulting in increased Ang II production. ${ }^{36}$ In this current study we showed that Ang II induced CTGF expression in atrial myocytes and cardiac fibroblasts. The atrial CTGF level was also highly correlated with atrial Ang II level in our paced AF pigs. We also showed that atrial dilatation was associated with elevated CTGF expression in humans. Our proposed mechanism for the evolution of AF is that both atrial stretch (atrial dilatation) and $\mathrm{AF}$ itself (rapid depolarization) result in increased release of 
Ang II, which induces increased CTGF expression and causes atrial fibrosis. Atrial fibrosis in turn makes the atrium more vulnerable to AF.

\section{Study Limitations}

Due to the small size of the tissue specimens, we did not measure the Ang II levels in human atrial tissues. We also did not test the effect of Ang II receptor antagonist on CTGF expression in the paced porcine AF model.

\section{Conclusion}

Our results demonstrate that CTGF expression is increased in the atria of human AF patients and in a porcine AF model. Ang II induced increased CTGF expression in both rat hearts and atrial fibroblast and myocyte cultures. Although more studies are needed to elucidate the signaling pathway, CTGF may play a vital role in atrial substrate remodeling.

\section{Acknowledgments}

This study was sponsored by a grant (97CGH-TMU-A2) from the Cathay General Hospital, Taipei, Taiwan.

\section{Disclosure}

Conflicts of interests: No.

\section{References}

1. Nattel S, Burstein B, Dobrev D. Atrial remodeling and atrial fibrillation: Mechanisms and implications. Circ Arrhythm Electrophysiol 2008; 1: $62-73$.

2. Eckstein J, Verheule S, de Groot NM, Allessie M, Schotten U. Mechanisms of perpetuation of atrial fibrillation in chronically dilated atria. Prog Biophys Mol Biol 2008; 97: 435-451.

3. Schotten U, de Haan S, Neuberger HR, Eijsbouts S, Blaauw Y, Tieleman $\mathrm{R}$, et al. Loss of atrial contractility is primary cause of atrial dilatation during first days of atrial fibrillation. Am J Physiol Heart Circ Physiol 2004; 287: H2324-H2331.

4. Wijffels MC, Kirchhof CJ, Dorland R, Allessie MA. Atrial fibrillation begets atrial fibrillation: A study in awake chronically instrumented goats. Circulation 1995; 92: 1954-1968.

5. Li D, Fareh S, Leung TK, Nattel S. Promotion of atrial fibrillation by heart failure in dogs: Atrial remodeling of a different sort. Circulation 1999; 100: 87-95.

6. Verheule S, Sato T, Everett T IV, Engle SK, Otten D, Rubart-von der Lohe $\mathrm{M}$, et al. Increased vulnerability to atrial fibrillation in transgenic mice with selective atrial fibrosis caused by overexpression of TGF- $\beta 1$. Circ Res 2004; 94: 1458-1465.

7. Young MJ. Mechanisms of mineralocorticoid receptor-mediated cardiac fibrosis and vascular inflammation. Curr Opin Nephrol Hypertens 2008; 17: 174-180.

8. Zhao W, Zhao T, Chen Y, Ahokas RA, Sun Y. Oxidative stress mediates cardiac fibrosis by enhancing transforming growth factor$\beta 1$ in hypertensive rats. Mol Cell Biochem 2008; 317: 43-50.

9. Lau LF, Lam SC. The CCN family of angiogenic regulators: The integrin connection. Exp Cell Res 1999; 248: 44-57.

10. Oemar B, Werner A, Garnier J, Do D, Godoy N, Nauck M, et al. Human connective tissue growth factor is expressed in advanced atherosclerotic lesions. Circulation 1997; 95: 831-839.

11. Ruperez M, Lorenzo O, Blanco-Colio LM, Esteban V, Egido J, Ruiz-Ortega M. Connective tissue growth factor is a mediator of angiotensin II-induced fibrosis. Circulation 2003; 108: 1499-1505.

12. Asakura M, Kitakaze M. Global gene expression profiling in the failing myocardium. Circ J 2009; 73: $1568-1576$.

13. Ahmed MS, Oie E, Vinge LE, Yndestad A, Oystein Andersen G, Andersson Y, et al. Connective tissue growth factor: A novel mediator of angiotensin II-stimulated cardiac fibroblast activation in heart failure in rats. J Mol Cell Cardiol 2004; 36: 393-404.

14. Lin CS, Lai LP, Lin JL, Sun YL, Hsu CW, Chen CL, et al. Increased expression of extracellular matrix proteins in rapid atrial pacinginduced atrial fibrillation. Heart Rhythm 2007; 4: 938-949.
15. Tsai CT, Lai LP, Kuo KT, Hwang JJ, Hsieh CS, Hsu KL, et al. Angiotensin II activates signal transducer and activators of transcription 3 via rac1 in atrial myocytes and fibroblasts: Implication for the therapeutic effect of statin in atrial structural remodeling. Circulation 2008; 117: 344-355.

16. Pellman J, Lyon RC, Sheikh F. Extracellular matrix remodeling in atrial fibrosis: Mechanisms and implications in atrial fibrillation. $J$ Mol Cell Cardiol 2010; 48: 461-467.

17. Everett TH, Olgin JE. Atrial fibrosis and the mechanisms of atrial fibrillation. Heart Rhythm 2007; 4: S24-S27.

18. Shimo T, Nakanishi T, Nishida T, Asano M, Kanyama M, Kuboki $\mathrm{T}$, et al. Connective tissue growth factor induces the proliferation, migration, and tube formation of vascular endothelial cells in vitro, and angiogenesis in vivo. J Biochem 1999; 126: 137-145.

19. Hishikawa K, Oemar BS, Tanner FC, Nakaki T, Luscher TF, Fujii T. Connective tissue growth factor induces apoptosis in human breast cancer cell line MCF-7. J Biol Chem 1999; 274: 37461-37466.

20. Manabe I, Shindo T, Nagai R. Gene expression in fibroblasts and fibrosis: Involvement in cardiac hypertrophy. Circ Res 2002; 91: 1103-1113.

21. Baudino TA, Carver W, Giles W, Borg TK. Cardiac fibroblasts: Friend or foe? Am J Physiol Heart Circ Physiol 2006; 291: H1015H1026.

22. Hosoda K, Nakao K, Mukoyama M, Saito Y, Jougasaki M, Shirakami $\mathrm{G}$, et al. Expression of brain natriuretic peptide gene in human heart. Production in the ventricle. Hypertension 1991; 17: 1152-1155.

23. Thum T, Borlak J. Gene expression in distinct regions of the heart. Lancet 2000; 355: 979-983.

24. Adam O, Lavall D, Theobald K, Hohl M, Grube M, Ameling S, et al. Rac1-induced connective tissue growth factor regulates connexin 43 and n-cadherin expression in atrial fibrillation. J Am Coll Cardiol 2010; 55: 469-480.

25. Touyz RM, Sventek P, Lariviere R, Thibault G, Fareh J, Reudelhuber $\mathrm{T}$, et al. Cytosolic calcium changes induced by angiotensin II in neonatal rat atrial and ventricular cardiomyocytes are mediated via angiotensin II subtype 1 receptors. Hypertension 1996; 27: 10901096.

26. Burstein B, Libby E, Calderone A, Nattel S. Differential behaviors of atrial versus ventricular fibroblasts: A potential role for plateletderived growth factor in atrial-ventricular remodeling differences. Circulation 2008; 117: 1630-1641.

27. Kerr CR, Humphries KH, Talajic M, Klein GJ, Connolly SJ, Green $\mathrm{M}$, et al. Progression to chronic atrial fibrillation after the initial diagnosis of paroxysmal atrial fibrillation: Results from the canadian registry of atrial fibrillation. Am Heart J 2005; 149: 489-496.

28. Garratt CJ, Duytschaever M, Killian M, Dorland R, Mast F, Allessie MA. Repetitive electrical remodeling by paroxysms of atrial fibrillation in the goat: No cumulative effect on inducibility or stability of atrial fibrillation. J Cardiovasc Electrophysiol 1999; 10: 1101 1108.

29. Stiles MK, John B, Wong CX, Kuklik P, Brooks AG, Lau DH, et al. Paroxysmal lone atrial fibrillation is associated with an abnormal atrial substrate: Characterizing the "second factor". J Am Coll Cardiol 2009; 53: 1182-1191.

30. Blom IE, Goldschmeding R, Leask A. Gene regulation of connective tissue growth factor: New targets for antifibrotic therapy? Matrix Biol 2002; 21: 473-482.

31. Shi-Wen X, Leask A, Abraham D. Regulation and function of connective tissue growth factor/CCN2 in tissue repair, scarring and fibrosis. Cytokine Growth Factor Rev 2008; 19: 133-144.

32. Grotendorst GR, Rahmanie H, Duncan MR. Combinatorial signaling pathways determine fibroblast proliferation and myofibroblast differentiation. FASEB J 2004; 18: 469-479.

33. Wang X, McLennan SV, Allen T, Tsoutsman T, Semsarian C, Twigg SM. Adverse effects of high glucose and free fatty acid on cardiomyocytes are mediated by connective tissue growth factor. Am J Physiol Cell Physiol 2009; 297: 1490-1500.

34. Ogi H, Nakano Y, Niida S, Dote K, Hirai Y, Suenari K, et al. Is structural remodeling of fibrillated atria the consequence of tissue hypoxia? Circ J 2010; 74: 1815-1821.

35. Yamashita T, Sekiguchi A, Iwasaki YK, Date T, Sagara K, Tanabe $\mathrm{H}$, et al. Recruitment of immune cells across atrial endocardium in human atrial fibrillation. Circ J 2010; 74: 262-270.

36. Tsai CT, Lai LP, Hwang JJ, Chen WP, Chiang FT, Hsu KL, et al. Renin-angiotensin system component expression in the HL-1 atrial cell line and in a pig model of atrial fibrillation. J Hypertens 2008; 26: $570-582$. 